\title{
PD-L1 Expression on Circulating CD34+ Hematopoietic Stem Cells Closely Correlated with T-cell Apoptosis in Chronic Hepatitis C Infected Patients
}

\author{
Hussein Abdellatif ${ }^{1,2}$, Gamal Shiha, \\ ${ }^{1}$ Department of Anatomy and Embryology, Faculty of Medicine, University of Mansoura, Mansoura, Egypt \\ ${ }^{2}$ Department of Anatomy, College of Medicine, University of Bisha, Bisha, Saudi Arabia \\ ${ }^{3}$ Department of Internal Medicine, Faculty of Medicine, University of Mansoura, Mansoura, Egypt \\ ${ }^{4}$ Head of Egyptian Liver Research Institute and Hospital (ELRIAH), Mansoura, Egypt
}

\begin{abstract}
Background and Objectives: Lack of understanding of the interplay between hematopoietic stem cells (HSCs) and the immune system has severely hampered stem cell research. Programmed death-1 (PD-L1) has been reported on parenchymal cells in patients with chronically inflamed livers and found to play an essential role in $\mathrm{T}$ cell homeostasis regulation. However, the bidirectional interaction between HSCs and lymphocytes remains elusive. Here, we aimed to get more insight into circulating CD34+ HSCs PD-L1 expression and T cell apoptosis in chronic HCV infected patients.

Methods: CD34+ HSCs were isolated and purified by immunomagnetic separation. PD-L1 expression was analyzed by quantitative PCR and flow cytometry. Furthermore, co-culture experiments between CD34+ HSCs and T-lymphocytes were established. T-cell lymphocyte apoptosis in peripheral blood and in cultures was detected.

Results: CD34+ HSCs constitutively express low levels of PD-L1. Its expression is up-regulated in chronic HCV infected patients. Moreover, PD-L1 expression on circulating CD34+ HSCs enhanced T cell apoptosis in peripheral blood and co-culture.

Conclusion: Our results suggest novel bidirectional interplay between HSCs and lymphocytes mediated by PD-L1 expression on CD34+ HSCs. PD-L1 expression correlated with T-cell lymphocyte apoptosis. This may contribute to immunomodulatory properties of HSCs which improves its use for allogeneic transplantation.
\end{abstract}

Keywords: CD34+ HSCs, PD-L1, B7-H1, T-lymphocytes, Apoptosis, HCV

Received: August 12, 2017, Revised: October 12, 2017,

Accepted: November 10, 2017, Published online: January 2, 2018

Correspondence to Hussein Abdellatif

Department of Anatomy and Embryology, Faculty of Medicine,

University of Mansoura, Mansoura 35516, Egypt

Tel: +2 01145919955, Fax: +20 (50) 2397900

E-mail: Hussein.abdullatif@hotmail.com

(c) This is an open-access article distributed under the terms of the Creative Commons Attribution Non-Commercial License (http://creativecommons.org licenses/by-nc/4.0/), which permits unrestricted non-commercial use, distribution, and reproduction in any medium, provided the original work is properly cited.

Copyright (c) 2018 by the Korean Society for Stem Cell Research

\section{Introduction}

Hepatitis $\mathrm{C}$ virus $(\mathrm{HCV})$ infection is a major leading cause of chronic liver disease (CLD) worldwide (1). Egypt (with the genotype IV as the most common) has the highest prevalence of HCV in the world, estimated nationally at $14.7 \%$ (2). The consequences of chronic HCV infection represent compelling health problems and is the most frequent cause of viral-related cirrhosis and liver cancer and the principal indication for liver transplantation worldwide (3). HCV causes persistent infection in $\sim 75-80 \%$ of patients. In these individuals, the function of $\mathrm{HCV}$-specific immune cells is impaired by ligation of inhibitory re- 
ceptors, the repertoire of which has expanded considerably in the past few years (4). B7-like molecules and their cognate receptors constitute important co-stimulatory pathways that control and fine-tune immune responses. In recent years, an array of new members of the B7 family has been identified, including B7-H1 (PD-L1) and B7-DC (PD-L2) (5). Both are ligands for programmed death-1 (PD-1), which is expressed on activated T and B cells (6-8). PD-L1 expression has been described to be induced in a variety of organs $(5,9)$. An overwhelming number of studies supported the role of PD-L1 as a negative regulator of T cell responses and suggest that PD-L1 promotes peripheral tolerance (10). Recently, hepatic accumulation and impaired apoptosis in $\mathrm{CD} 8+\mathrm{T}$ cells have been observed in experimental autoimmune hepatitis in PD-L1-deficient mice leading to accelerated damage of hepatocytes (11). Golden-Mason et al. (12) and Radziewicz et al. (13) showed that PD-1/PD-L1 pathway was critical in persistence of $\mathrm{HCV}$ infection and represented a potential novel target for reversible immune dysfunction.

Acute and chronic liver injuries with different forms of cellular damage induce recruitment of stem cells from the bone marrow $(\mathrm{BM})$ and their involvement in liver regeneration (14). They represent the third progeny, after hepatocytes and hepatic progenitor cells that contribute to liver repair. PD-L1 (B7-H1) was reported recently in non-parenchymal liver cells $(15,16)$. mesenchymal stem cells (17) and cultured bone marrow-derived mast cells (18). Here we analyzed the expression of PD-L1 on BM-derived HSCs and provide data suggesting novel bidirectional interaction with immune cells and their possible correlation with T-cell apoptosis in chronic HCV infected patients.

\section{Materials and Methods}

\section{Study participants}

50 subjects were recruited and divided into two groups: chronic HCV-infected patients $(n=30)$, and healthy controls $(n=20)$. All patients were prospectively recruited from the outpatient clinic of the Liver Hospital, Mansoura, Egypt, during the period from December 2016 to March 2017. All HCV-infected patients were negative for other chronic liver diseases including viral hepatitis A and B, which were defined by seronegativity with enzyme immunoassays. Patients with a history of habitual alcohol consumption or hepatocellular carcinoma, previous interferon treatment, decompensated liver disease (ascites, jaundice, variceal hemorrhage, or encephalopathy) and liver transplantation were excluded from the study. HCV infection was confirmed by detectable plasma HCV viral load measured by PCR assay using (COBAS Ampliprep/COBAS TaqMan; Roche Diagnostics AQ5, USA) for HCV-RNA. Healthy donors were negative for HCV, HBV and HIV-1 infection. Our study was approved by the local ethics committee and all patients provided written informed consent before their enrollment in the study.

\section{Clinical biochemical tests}

Liver associated enzymes including ALT, AST and other variables such as albumin, bilirubin, platelets and WBCs count were measured by clinical standardized methods. Full baseline characteristics and virological data of enrolled subjects are summarized in Table 1.

Flow cytometric analysis of circulating CD34+ HSCs Blood samples were obtained in the outpatient depart-

Table 1. Clinical characteristics of the study population

\begin{tabular}{lccc}
\hline \multicolumn{1}{c}{ Parameters } & $\mathrm{CHC}(\mathrm{n}=30)$ & Control $(\mathrm{n}=20)$ & $\mathrm{p}$ value \\
\hline Male/Female & $18 / 12$ & $13 / 7$ & 0.935 \\
Age (years) & $44.8 \pm 13.7$ & $45.15 \pm 12.1$ & $<0.0001^{*}$ \\
ALT $(\mathrm{IU} / \mathrm{L})$ & $50.1 \pm 17.6$ & $18.3 \pm 5.1$ & $<0.0001^{*}$ \\
Total bilirubin $(\mathrm{mg} / \mathrm{dl})$ & $2.8 \pm 0.98$ & $0.6 \pm 0.22$ & $<0.0001^{*}$ \\
Albumin $(\mathrm{g} / \mathrm{dl})$ & $3.36 \pm 0.7$ & $4.1 \pm 0.59$ & 0.445 \\
WBC count $\left(\times 10^{3} / \mu \mathrm{l}\right)$ & $7.9 \pm 1.7$ & $6.8 \pm 2.1$ & 0.191 \\
Platelet count $\left(\times 10^{9} / \mathrm{L}\right)$ & $241.3 \pm 59.2$ & $275.9 \pm 56.2$ & $\mathrm{ND}$ \\
HCV genotyping $(4 \mathrm{a} / 4 \mathrm{C})$ & $16 / 14$ & $\mathrm{ND}$ & \\
HCV RNA $(\log 10 \mathrm{l} / \mathrm{l} / \mathrm{ml})$ & $5.7 \pm 1.3$ & 0 & \\
Prior medication for HCV & 0 & & \\
\hline
\end{tabular}

CHC: chronic hepatitis C, ALT: alanine aminotransferase, WBC: white blood cells, HCV: hepatitis C virus, ND: not determined. Data are expressed as mean $\pm \mathrm{SD}$.

*Indicates significant deviation from the control as indicated by $\mathrm{p}$ value $<0.05$. 
ment for the study groups and also for the healthy control subjects. Ten milliliters of blood was drawn from the antecubital vein. Mononuclear cells (MNCs) were then isolated by density-gradient centrifugation of Ficoll 400 (Ficoll $^{\circledR}$ Paque Plus, GE17-1440-02, Sigma-Aldrich, Germany) as previously described (19). Then CD34+ cells were isolated by using CD34+ MiniMacs high-gradient magnetic separation column (Miltenyi Biotec, Bergisch Gladbach, Germany) following manufacturer's instruction. The isolated CD34+ cells were then analyzed by conventional dual color immunofluorescence using PE-conjugated anti-CD34, vioblue-conjugated anti-CD45 antibodies (Miltenyi Biotec, Germany). Surface expression of PD-L1 on isolated CD34+ HSCs was analyzed by using APC-conjugated anti-PD-L1 (clone, 130021) antibodies (FAB1561A, $\mathrm{R} \& \mathrm{D}$ System, USA). PE, vioblue or APC-conjugated anti-mouse IgG was used as isotype control. After washing with PBS, the cells were fixed with $1 \%$ paraformaldehyde and then analyzed by flow cytometry (MACSQuant Analyser, 2440, Miltenyi Biotec, Germany). Data were analyzed using MACSQuantify software (version 2.4). Live cells were identified by forward and side scatter. Gating was based upon isotype controls. Peripheral blood mononuclear cells (PBMCs) and HSCs were identified as CD45 and CD34 positive, respectively. The assays for HSCs and PD-L1 expression in each sample were performed in duplicate and the mean levels were reported. The results were expressed as a percentage and mean fluorescence intensity (MFI) per sample. Intra-assay variability based on repeated measurement of the same blood sample was low with a mean coefficient of variance of $4.3 \%$ in CHC patients and $4.15 \%$ in healthy control subjects.

\section{Peripheral blood T- cell apoptosis assay}

Peripheral blood T cell subset measurements were performed during each follow-up review. Percentages of $\mathrm{T}$ cell subsets were determined on $100 \mu$ l ethylenediamine tetra-acetic acid (EDTA) blood sample, using a dual-color direct immunofluorescence method (Miltenyi Biotec, Germany). CD3 + T cells were autogated and analyzed for CD8 expression using CD8/CD3 cell dual staining method. PE-conjugated anti CD3 and APC-conjugated anti CD8 were used for analysis. PE or APC-conjugated anti-mouse $\mathrm{IgG}$ was used as isotype control. Erythrocytes were lysed with lysis buffer (0.155 M NH4 Cl, 0.012 M NaHCO3, 0.1 $\mathrm{mM}$ EDTA, $\mathrm{pH}$ 7.2) for $5 \mathrm{~min}$ at room temperature. After washing with PBS, cells were stained simultaneously with FITC-conjugated Annexin V and propidium iodide (PI) (both from Miltenyi Biotec, Germany) according to the manufacturer's instructions. During flow analysis, a live acquisition gate was placed on lymphocytes based on FSC/SSC profile. Side and forward angle light scattering were used to electronically gate the cells of choice and to exclude debris. Ten thousand events within the gate region were collected for each sample. Rare contaminating events were excluded on the basis of FSC/SSC. The percentages of $\mathrm{CD} 3+$ and $\mathrm{CD} 8+\mathrm{T}$ cells that were annexin $\mathrm{V}$ and/or PI positive were measured by MACSQuant Analyzer using MACSQuantify software (version 2.4).

\section{Effect of CD34+ HSCs on T-cell apoptosis}

CD34+ HSCs and MNCs were prepared as described above. T cells $\left(1 \times 10^{6}\right)$ were cultured alone or co-cultured with CD34+ HSCs $\left(1 \times 10^{5}\right)$ in ratio of $1: 10$ or stimulated with PHA (50 mg/ml final concentration) for 3 days, harvested and quantified, stained with Annexin V kit (Miltenyi Biotec, Germany) and analyzed by flow cytometry (MACSQuant Analyzer, 2440).

\section{Reverse transcriptase-polymerase chain reaction for PD-Ll expression on HSCs}

The expression of PD-L1 on isolated CD34+ HSCs was assessed by reverse transcription- polymerase chain reaction (RT-PCR) amplification using gene-specific primers (PD-L1, F:5'-CACGGTTCCCAAGGACCTAT-3'and-reverse:5'-TGGAGGATGTGCCAGAGGTA'). B-actin was ampli fied to demonstrate the integrity and the use of equal amounts of RNA and used as internal control (F: 5'-agcacagagcctcgcctttg-3', R: 5'-tgacgatgccgtgctcgatg-3', 267 bp). Total cellular RNA was extracted from purified CD34+ cells by using Trizol reagent (Invitrogen, CA, USA). RNA samples were treated with $10 \mu 1$ DNase I (Roche Diagnostics, USA) per $\mathrm{ml}$ at $37^{\circ} \mathrm{C}$ for $30 \mathrm{~min}$ to decrease the contamination of genomic DNA, then heated at $70^{\circ} \mathrm{C}$ for 5 min to inactivate DNase I. Reverse transcription was performed using the (LightCycler ${ }^{\circledR} 480$ System, Roche Diagnostics AQ5, USA) following manufacturer's instructions. The expression of different transcripts was assessed by PCR amplification following standard protocols. The PCR products were analyzed on a $1 \%$ agarose gel stained with ethidium bromide.

\section{Statistical analysis}

Results are expressed as means \pm SD (range) or percent. Comparison between groups was made using the Student's unpaired t-test. Pearson correlation analysis of PD-L1 expression on circulating CD34+ HSCs and T-cell apoptosis was performed. Differences were considered statistically significant at $\mathrm{p}<0.05$. All calculations were performed using statistical computer package GraphPad Prism 7.03 
for Windows.

\section{Results}

\section{Characteristics of study populations}

Two groups of participants were recruited in this study: chronic HCV-infected patients and healthy controls. The demographic and laboratory characteristics of all participants were summarized in Table 1.

\section{CD34+ HSCs in chronic HCV-infected patients}

In an attempt to quantitatively analyze the circulating $\mathrm{CD} 34+$ cells in the peripheral blood of patients, the aliquots of blood samples of $30 \mathrm{CHC}$ patients and 20 healthy controls were assessed by two-color flow cytometry. Cells were first gated according to forward/side scatter analysis (Fig. 1A). Then cells were further gated by CD45 positive staining (Fig. 1B). A representative of double-positive cells $(\mathrm{CD} 34+/ \mathrm{CD} 45+)$ from one CHC patient is shown in Fig. 1C. As shown in Fig. 2, a baseline of the percentage of $\mathrm{CD} 34+/ \mathrm{CD} 45+$ cells in the PBMCs ranged from 0.01 to $1.3 \%(0.5 \pm 0.42 \%)$ in healthy controls. In comparison with healthy controls, a significant increase in the percentage of circulating CD34+ cells, which ranged from 0.9 to $14.9 \%(5.4 \pm 3.7, \mathrm{p}<0.0001)$, were observed in $\mathrm{CHC}$ patients. The average numbers of circulating leucocytes were $\left(5.9 \pm 2 \times 10^{3} / \mu 1\right)$ in healthy controls and $(6.82 \pm 1.8$ $\left.\times 10^{3} / \mu 1\right)$ in CHC patients. No significant difference was found between two groups ( $\mathrm{p}$ value $>0.05$ ) suggesting that elevated CD34+ cells in patients are not due to the elevation of circulating leucocytes.
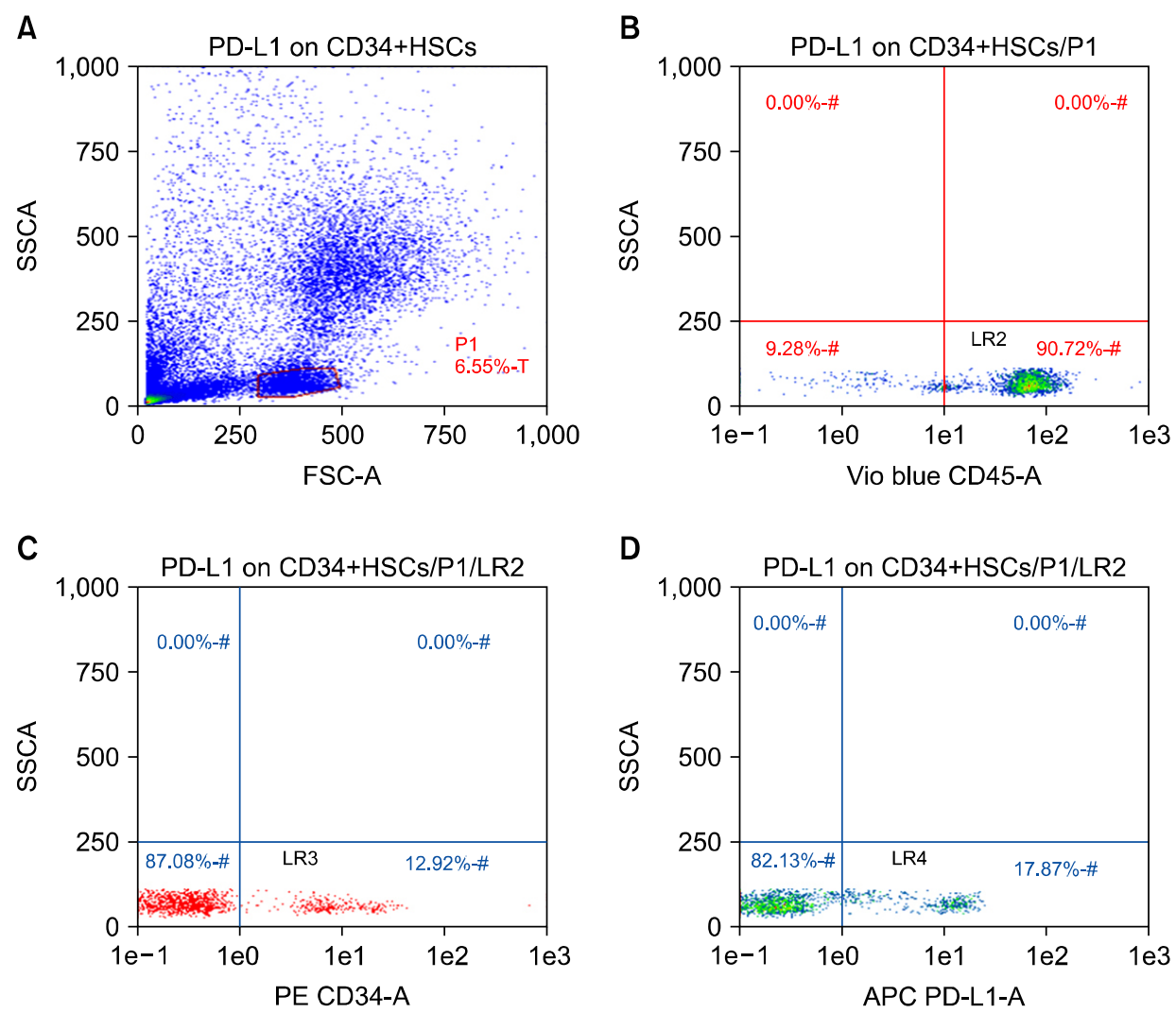

Fig. 1. PD-L1 expression on CD34+ HSCs in peripheral blood of chronic HCV-infected patients by flow cytometry. The peripheral blood $\mathrm{CD} 34+$ cells of patients and healthy controls were isolated by using MiniMacs high-gradient magnetic separation column and subsequently analyzed by flow cytometry using anti-CD45 and anti-CD34 antibodies. (A) A representative plot of enriched leukocytes shown by forward versus side scatter. The P1 gate represents the isolated PBMCs region. (B) The events in gate P1 are then displayed on a CD45 vs. SSC dot plot and a second gate (LR2) is produced to include the cluster of CD45 + events. (C) This plot is obtained by plotting the events that are fulfilling the criteria of gates P1 and LR2 (sequential gating). Cells forming a cluster with characteristic positivity to CD34 antibody are displayed in this plot creating the region LR3. (D) This plot is created by displaying cells that are positive for both CD45 and CD34 antibodies (LR3). Cells in lower right quadrant LR-4 are those with positive expression of PD-L1. 


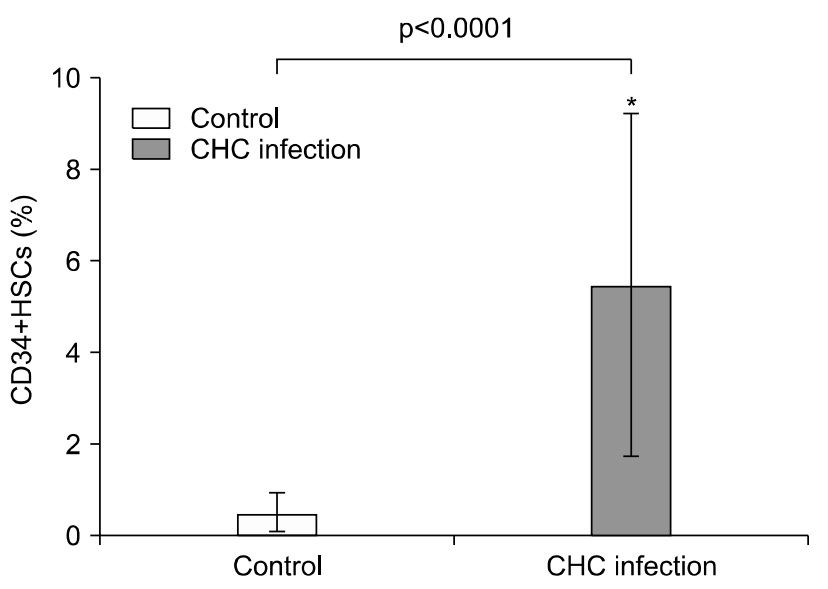

Fig. 2. Elevation of $\mathrm{CD} 34+\mathrm{HSCs}$ in the peripheral blood of $\mathrm{CHC}$ patients. A Percentage of CD34+ cells in PBMCs fraction. Data represent the percentages of circulating CD34+ cells in the PBMCs fractions of $30 \mathrm{CHC}$ patients and 20 healthy controls. Values are expressed as mean $\pm \mathrm{SD}$. *indicates significant deviation from the control as indicated by $\mathrm{p}$ value $<0.05$.
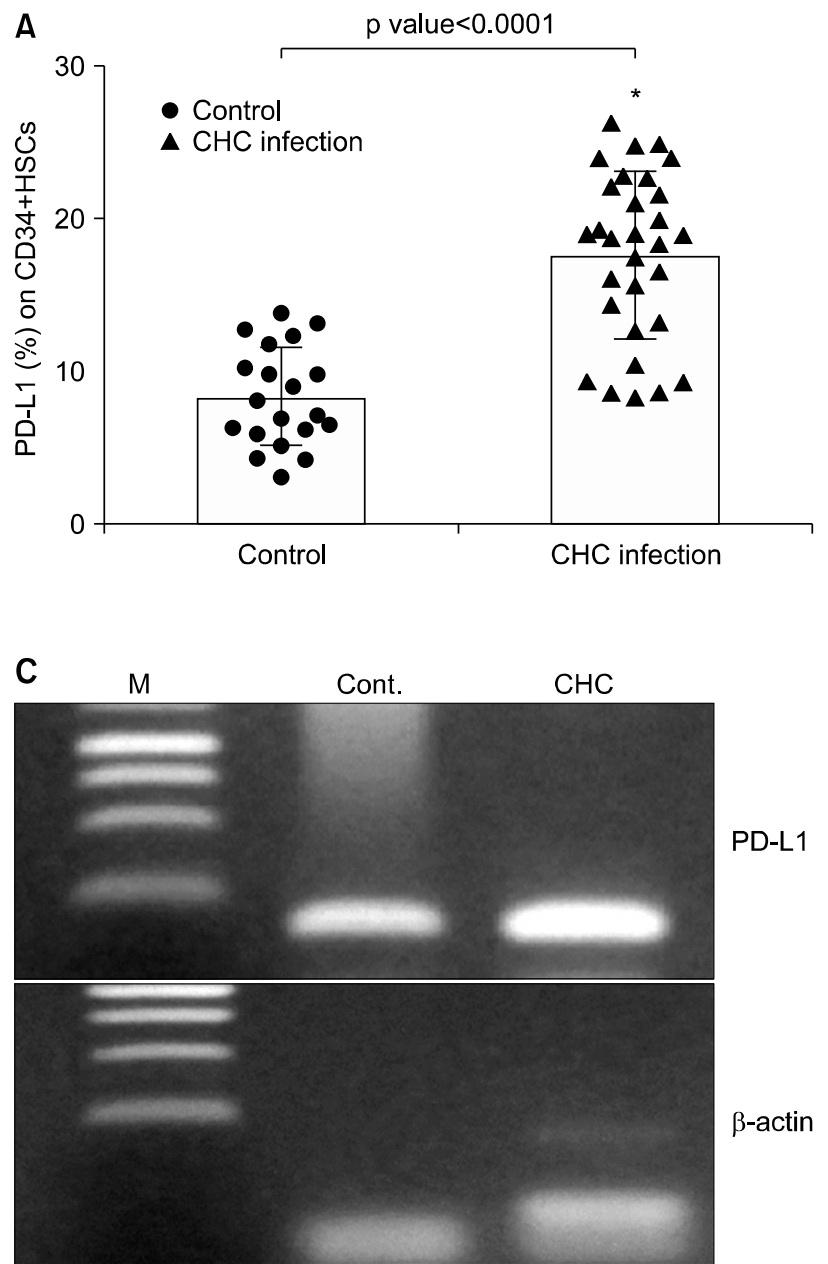

\section{PD-Ll expression level was elevated on CD34+ HSCs of $\mathrm{CHC}$ infected patients}

Initially, we analyzed PD-L1 mRNA expression in isolated circulating CD34+ HSCs. In accordance with previous studies analyzing hematopoietic cells $(17,20)$ we detected PD-L1 mRNA expression in isolated CD34 cells (Fig. 3C). In addition to this, the PD-L1 expression levels on CD34+ HSCs in all 30 chronic HCV-infected patients and healthy controls were analyzed by FCM. Representative FCM plots of circulating PD-L1-positive CD34+ HSCs in one chronic HCV-infected patient are presented in Fig. 1D. Both the percentage of PD-L1-positive CD34 cells and the mean fluorescence intensity (MFI) of PD-L1 expression were used to evaluate the PD-L1 expression level. Our results showed that the percentage of PD-L1-positive CD34+ HSCs in chronic HCV- infected patients (17.5 \pm 5.4$)$ was more than that in normal controls $(8.3 \pm 3.2, \mathrm{p}<0.0001)$ (Fig. 3A). Also, the MFI of PD-L1 expression in chronic HCV- infected patients (34.4 \pm 11.2$)$ was significantly in-

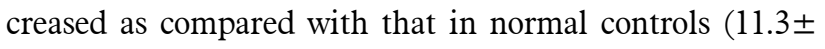

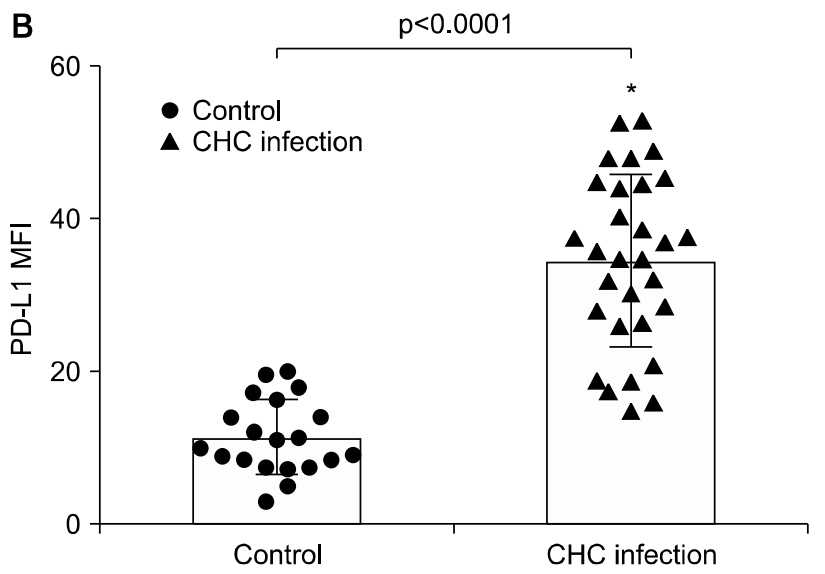

Fig. 3. PD-L1 expression on CD34+ HSCs in peripheral blood of $\mathrm{CHC}$ patients $(\mathbf{\Delta})$ and healthy controls $(\bullet)$. Data were presented as percentage of positive cells (A) and mean fluorescence intensity (B). Graphs showed vertical scatter plots and mean columns. *indicates significant deviation from the control as indicated by $p$ value $<0.05$. (C) Detection of PD-L1 transcript in purified CD34+ HSCs of CHC patients by RT-PCR. CDNA was synthesized from total RNA of purified CD34+ cells and $\beta$-actin was used as an internal control to demonstrate equal loading and integrity of RNA. M, marker, lane 1 healthy control (cont.) and lane $2 \mathrm{CHC}$ patients. 
4.8, $\mathrm{p}<0.0001)$ (Fig. 3B).

\section{Expression of PD-L1 in circulating CD34+ HSCs paralleled with T-cell apoptosis}

Correlation between PD-L1 expression levels on CD34+ HSCs and degree of CD-8 T cell apoptosis was summarized in Fig. 4. Numbers of apoptotic CD8 $+\mathrm{T}$ cells were significantly increased in $\mathrm{CHC}$ patients $(9.9 \pm 4)$ when compared with healthy controls $(1.2 \pm 0.4, \mathrm{p}<0.0001)$ identified by cells positive for Annexin V-FITC antibody (Fig. 5). PD-L1 expression on CD34+ HSCs (percentage and MFI) was strongly correlated with CD8 + T-cell apoptosis (Fig. 4A and B, r=0.8979 and 0.8448 respectively, $p$ $<0.0001)$ in patients chronically infected with hepatitis C
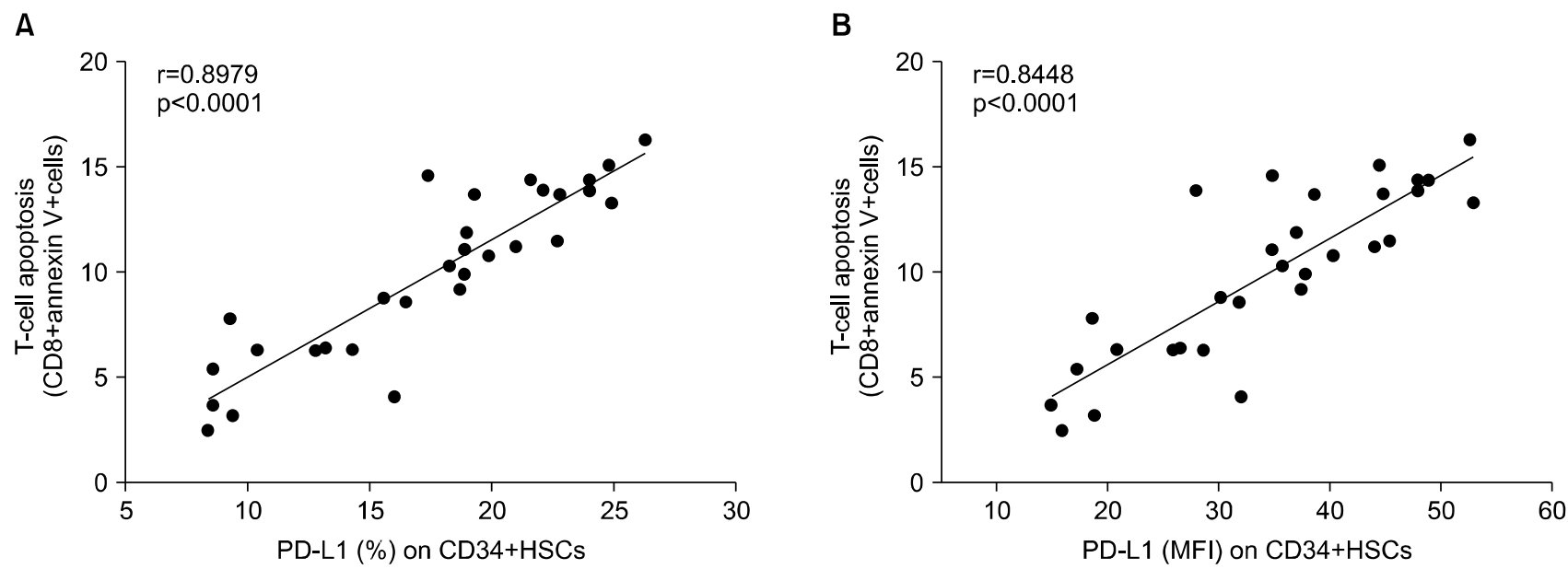

Fig. 4. Correlation analysis of expression of PD-L1 on CD34+HSCs and T-cell apoptosis (CD8+ Annexin V+ cells) in chronic HCV infected patients. (A) Percentage (\%) of PD-L1 expression (B) Mean fluorescence intensity (MFI). $r=0.8979$ and 0.8448 respectively. $p<0.0001$.
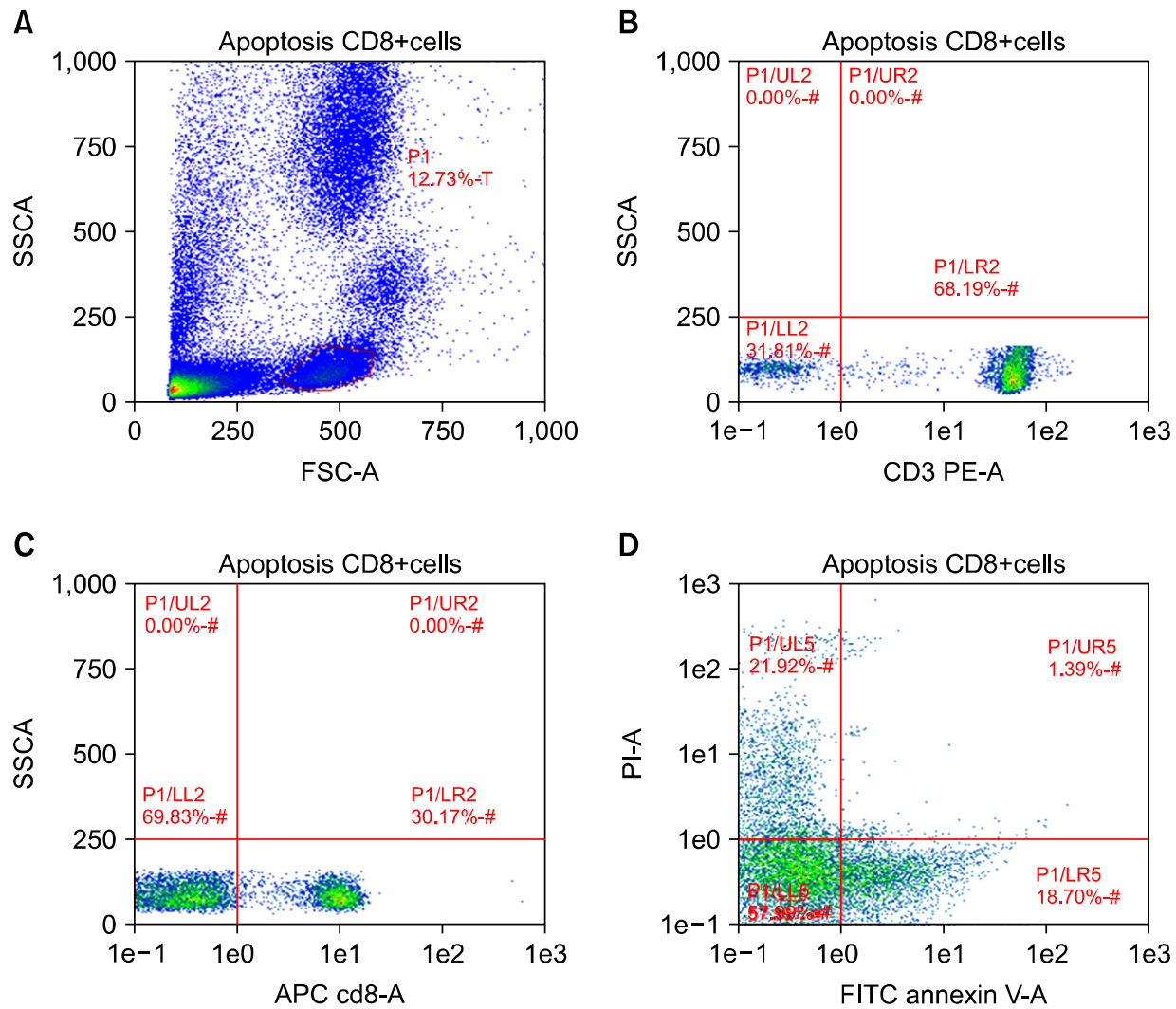

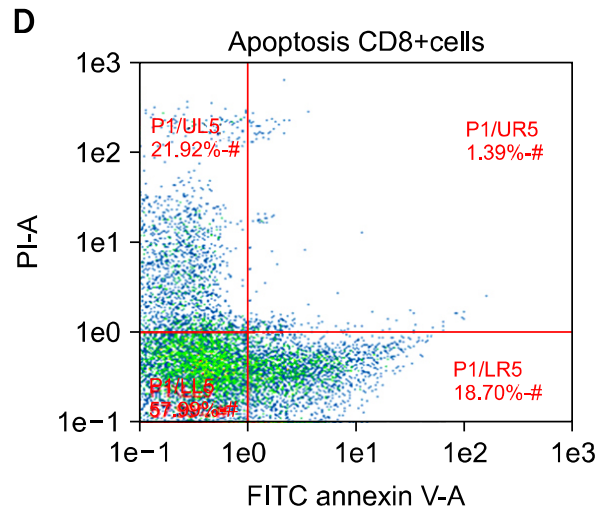

Fig. 5. Expression of PD-L1 on CD34+ HSCs mediated CD-8 T-cell apoptosis in peripheral blood of chronic $\mathrm{HCV}$-infected patients. Apoptosis in T-cells was examined by flow cytometric analysis using AnnexinV/PI staining. Numbers of apoptotic cells (positive for Annexin $\mathrm{V}$ stain) are indicated in plot D. One of three independent experiments is depicted. 
virus. T-cells apoptosis using Annexin V kit was detected when cells were co-cultured HSCs, the ratio of T-cell apoptosis was $1.3 \pm 0.36$ in absence of CD34+ HSCs, but $10.35 \pm 4.9$ in presence of CD34+HSCs ( $\mathrm{T}$ - cell apoptosis rate was statistically different, $\mathrm{p}<0.0001)$.

\section{Discussion}

During the last decades, host adaptive immune responses and especially the effects of antiviral CD8 $+\mathrm{T}$ cells have been shown to play an essential role in the elimination or control of the most important human viral infections. Thus, a virus-specific CD8 + T-cell response can clear the virus by cytolytic and non-cytolytic effector mechanisms. Importantly, however, these viral infections can lead to viral persistence. Compelling progress has been achieved in understanding mechanisms of T-cell effector function and failure. These findings are important for understanding of immunological factors of virus-host interactions, as well as antiviral vaccine development strategies against $\mathrm{HCV}$ and viral immune-therapies that help to cure chronic HCV infections (21). However, there are still several open questions that need to be addressed in order to completely explore T-cell failure in viral hepatitis. Indeed, it worth noting that while the effector functions of HCV-specific CD8 + T cells are mainly elucidated, other aspects of the immune response of CD8 $+\mathrm{T}$ cells are less understood. For example, the precise mechanisms of liver homing of virus-specific $\mathrm{T}$ cells, effect of general proliferation signals mediated by HCV infection on virus-specific $\mathrm{T}$ cells, impact of stem cell-mediated liver repair and cell to cell contact on T- cells are still not completely discovered. Thus understanding these factors may help to catch on the underlying mechanisms of $\mathrm{T}$ cells failure and thus chronic disease progression.

We demonstrated that circulating CD34+ HSCs constitutively express low levels of PD-L1, while its expression is strongly enhanced by activated $\mathrm{T}$ cells and viral infection. Moreover, PD-L1 expression on HSCs induces apoptosis in $\mathrm{T}$ cells. The detection of constitutive PD-L1 expression in human HSCs is novel and surprising, since a recent study analyzing PD-L1 expression detected antibody staining exclusively in culture expanded murine hematopoietic stem cells (22). Currently, only a few studies have analyzed PD-L1 expression in tissues from diff erent species. In some of those, different PD-L1 tissue expression patterns were observed comparing tissues of murine and human origin (23-27). Therefore, human HSCs were analyzed confirming PD-L1 expression species independently in circulating HSCs.
Accumulating evidence has revealed that the BM-derived human HSCs can migrate to the liver and contribute to liver regeneration. Results from gender mismatch liver transplantation studies proposed that BM-derived HSCs of host origin can differentiate into hepatocytes and cholangiocytes in transplanted livers, while hepatocyte chimerism was present in the patients affected by recurrent hepatitis $(28,29)$. Wynn, 2007 stated that inflammation is a critical factor in the initiation and maintenance of liver fibrogenesis and cirrhosis from hepatitis viral infection. Inflammation reactions and damaged cells in liver release inflammatory mediators, such as TGF-betal and TNF-alpha, which can recruit reacting cells in circulating blood to the liver (30). Thus, it seems that elevated CD34+ levels in peripheral blood of CHC patients are related to persistent liver inflammation and imbalance between injury and endogenous repair capabilities.

Our results demonstrate PD-L1 mRNA expression in HSCs isolated from patients with chronic HCV infection, in addition to its expression in quiescent cells (isolated from healthy controls) but at lower levels (by both positive percent expression and mean fluorescent intensity). In line with these findings, Zheng et al. (22) determined the expression of CD274 (PD-L1) on freshly isolated and culture expanded human cord blood HSCs. While only $\sim 10 \%$ of freshly isolated human CD34+ cells express CD274 on their surface, the CD274+ population increased to more than $50 \%$ after culture activation. Basic expression but even more inducible induction of PD-L1 on HSCs may have several implications. The observed profound up-regulation of PD-L1 expression on circulating HSCs may serve as a part of a protective negative feedback mechanism in $\mathrm{T}$ cell-mediated inflammatory events. Interestingly, a study in PD-L1-deficient mice suggested that PD-L1 is a key protein regulating the accumulation and deletion of intrahepatic CD8 + T cells (31). We found increased levels of PD-L1 upon viral infection (Fig. 3A and B). In line with our findings, previous studies found an up-regulation of PD-L1 expression in airway epithelial cells in response to double-stranded RNA (32) and in lymphocytes in response to HIV infection (27). Interestingly, there was a strong correlation between degree of PD-L1 expression and T-cell apoptosis detected by Annexin V staining in both peripheral blood and ex-vivo when isolated CD34+ HSCs were co-cultured with $\mathrm{T}$ lymphocytes $(r=0.8979$, $\mathrm{p}<0.0001)$.

Our findings may shed new light on bidirectional interaction between CD34+ bone marrow (BM) derived HSCs and lymphocytes. HSCs isolated from peripheral blood of healthy controls express low level of PD-L1. Exposure to 
general inflammatory and proliferation signals mediated by chronic HCV infection results in up-regulation of PD-L1 on HSCs. That, in turn, induces apoptosis of activated lymphocytes. Thus, circulating HSCs beside its role in liver regenerative process and restoration of liver mass upon chronic infection may contribute to immune tolerance induction by deletion of activated $\mathrm{T}$ cells through induction of apoptosis. This may provide new insight on the possibility of isolation and culture expansion of HSCs and may benefit allogeneic transplantation for patients.

The study has limitations; first, only PD-L1 was detected in our work, other co-stimulatory molecules expressed on stem cells that can modulate the immune response were not elucidated. Second, despite our interesting findings, the sample size of our series is relatively small. All conclusions based on our results are, therefore, tentative and need further support from well-controlled clinical studies of a larger scale with a wide range of study subjects.

In summary, our study demonstrated that PD-L1 is readily expressed upon HSCs. Its expression is up-regulated with chronic HCV infection. There is strong correlation between PD-L1 expression on HSCs and degree of T-cell lymphocyte apoptosis. Expression of such an immune inhibitory signal on HSCs may provide new insight into the process of allogeneic transplantation of HSCs. Cellular mechanism by which PD-L1 co-stimulates T cell response and in other circumstances these responses are inhibited remain elusive and need to be explored further.

\section{Acknowledgments}

We thank Liver Hospital (Mansoura, Egypt) for providing well equipped laboratories and technical support.

\section{Potential Conflict of Interest}

The authors declare that they have no competing interests related to this article.

\section{References}

1. Alter MJ, Kruszon-Moran D, Nainan OV, McQuillan GM, Gao F, Moyer LA, Kaslow RA, Margolis HS. The prevalence of hepatitis $\mathrm{C}$ virus infection in the United States, 1988 through 1994. N Engl J Med 1999;341:556-562

2. Frank C, Mohamed MK, Strickland GT, Lavanchy D, Arthur RR, Magder LS, El Khoby T, Abdel-Wahab Y, Aly Ohn ES, Anwar W, Sallam I. The role of parenteral antischistosomal therapy in the spread of hepatitis $\mathrm{C}$ virus in Egypt. Lancet 2000;355:887-891

3. Lok AS, Seeff LB, Morgan TR, di Bisceglie AM, Sterling
RK, Curto TM, Everson GT, Lindsay KL, Lee WM, Bonkovsky HL, Dienstag JL, Ghany MG, Morishima C, Goodman ZD. Incidence of hepatocellular carcinoma and associated risk factors in hepatitis C-related advanced liver disease. Gastroenterology 2009;136:138-148

4. McMahan RH, Golden-Mason L, Nishimura MI, McMahon BJ, Kemper M, Allen TM, Gretch DR, Rosen HR. Tim-3 expression on PD-1+ HCV-specific human CTLs is associated with viral persistence, and its blockade restores hepatocyte-directed in vitro cytotoxicity. J Clin Invest 2010; 120:4546-4557

5. Griffith TS, Brunner T, Fletcher SM, Green DR, Ferguson TA. Fas ligand-induced apoptosis as a mechanism of immune privilege. Science 1995;270:1189-1192

6. Dong H, Zhu G, Tamada K, Chen L. B7-H1, a third member of the B7 family, co-stimulates T-cell proliferation and interleukin-10 secretion. Nat Med 1999;5:1365-1369

7. Freeman GJ, Long AJ, Iwai Y, Bourque K, Chernova T, Nishimura H, Fitz LJ, Malenkovich N, Okazaki T, Byrne MC, Horton HF, Fouser L, Carter L, Ling V, Bowman MR, Carreno BM, Collins M, Wood CR, Honjo T. Engagement of the PD-1 immunoinhibitory receptor by a novel B7 family member leads to negative regulation of lymphocyte activation. J Exp Med 2000;192:1027-1034

8. Latchman Y, Wood CR, Chernova T, Chaudhary D, Borde M, Chernova I, Iwai Y, Long AJ, Brown JA, Nunes R, Greenfield EA, Bourque K, Boussiotis VA, Carter LL, Carreno BM, Malenkovich N, Nishimura H, Okazaki T, Honjo T, Sharpe AH, Freeman GJ. PD-L2 is a second ligand for PD-1 and inhibits T cell activation. Nat Immunol 2001;2:261-268

9. Oei E, Kalb T, Beuria P, Allez M, Nakazawa A, Azuma M, Timony M, Stuart Z, Chen H, Sperber K. Accessory cell function of airway epithelial cells. Am J Physiol Lung Cell Mol Physiol 2004;287:L318-L331

10. Subudhi SK, Alegre ML, Fu YX. The balance of immune responses: costimulation verse coinhibition. J Mol Med (Berl) 2005;83:193-202

11. Dong H, Zhu G, Tamada K, Flies DB, van Deursen JM, Chen L. B7-H1 determines accumulation and deletion of intrahepatic CD8(+) T lymphocytes. Immunity 2004;20: 327-336

12. Golden-Mason L, Palmer B, Klarquist J, Mengshol JA, Castelblanco N, Rosen HR. Upregulation of PD-1 expression on circulating and intrahepatic hepatitis $\mathrm{C}$ virus-specific $\mathrm{CD} 8+\mathrm{T}$ cells associated with reversible immune dysfunction. J Virol 2007;81:9249-9258

13. Radziewicz H, Ibegbu CC, Fernandez ML, Workowski KA, Obideen K, Wehbi M, Hanson HL, Steinberg JP, Masopust D, Wherry EJ, Altman JD, Rouse BT, Freeman GJ, Ahmed $\mathrm{R}$, Grakoui A. Liver-infiltrating lymphocytes in chronic human hepatitis $\mathrm{C}$ virus infection display an exhausted phenotype with high levels of PD-1 and low levels of CD127 expression. J Virol 2007;81:2545-2553

14. Di Campli C, Piscaglia AC, Giuliante F, Rutella S, Bonanno G, Zocco MA, Ardito F, Nuzzo G, Mancuso S, 
Leone G, Gasbarrini G, Pola P, Gasbarrini A. No evidence of hematopoietic stem cell mobilization in patients submitted to hepatectomy or in patients with acute on chronic liver failure. Transplant Proc 2005;37:2563-2566

15. Iwai Y, Terawaki S, Ikegawa M, Okazaki T, Honjo T. PD-1 inhibits antiviral immunity at the effector phase in the liver. J Exp Med 2003;198:39-50

16. Yu MC, Chen $\mathrm{CH}$, Liang X, Wang L, Gandhi CR, Fung JJ, Lu L, Qian S. Inhibition of T-cell responses by hepatic stellate cells via B7-H1-mediated T-cell apoptosis in mice. Hepatology 2004;40:1312-1321

17. Augello A, Tasso R, Negrini SM, Amateis A, Indiveri F, Cancedda R, Pennesi G. Bone marrow mesenchymal progenitor cells inhibit lymphocyte proliferation by activation of the programmed death 1 pathway. Eur J Immunol 2005; 35:1482-1490

18. Nakae S, Suto H, Iikura M, Kakurai M, Sedgwick JD, Tsai M, Galli SJ. Mast cells enhance $\mathrm{T}$ cell activation: importance of mast cell costimulatory molecules and secreted TNF. J Immunol 2006;176:2238-2248

19. Chironi G, Walch L, Pernollet MG, Gariepy J, Levenson J, Rendu F, Simon A. Decreased number of circulating $\mathrm{CD} 34+\mathrm{KDR}+$ cells in asymptomatic subjects with preclinical atherosclerosis. Atherosclerosis 2007;191:115-120

20. Rodig N, Ryan T, Allen JA, Pang H, Grabie N, Chernova T, Greenfield EA, Liang SC, Sharpe AH, Lichtman AH, Freeman GJ. Endothelial expression of PD-L1 and PD-L2 down-regulates CD8 $+\mathrm{T}$ cell activation and cytolysis. Eur J Immunol 2003;33:3117-3126

21. Schmidt J, Blum HE, Thimme R. T-cell responses in hepatitis $\mathrm{B}$ and $\mathrm{C}$ virus infection: similarities and differences. Emerg Microbes Infect 2013;2:e15

22. Zheng J, Umikawa $M$, Zhang S, Huynh $H$, Silvany R, Chen BP, Chen L, Zhang CC. Ex vivo expanded hematopoietic stem cells overcome the MHC barrier in allogeneic transplantation. Cell Stem Cell 2011;9:119-130

23. Brown JA, Dorfman DM, Ma FR, Sullivan EL, Munoz O, Wood CR, Greenfield EA, Freeman GJ. Blockade of programmed death-1 ligands on dendritic cells enhances $\mathrm{T}$ cell activation and cytokine production. J Immunol 2003;170:
$1257-1266$

24. Bennett F, Luxenberg D, Ling V, Wang IM, Marquette K, Lowe D, Khan N, Veldman G, Jacobs KA, Valge-Archer VE, Collins M, Carreno BM. Program death-1 engagement upon TCR activation has distinct effects on costimulation and cytokine-driven proliferation: attenuation of ICOS, IL-4, and IL-21, but not CD28, IL-7, and IL-15 responses. J Immunol 2003;170:711-718

25. Mazanet MM, Hughes CC. B7-H1 is expressed by human endothelial cells and suppresses $\mathrm{T}$ cell cytokine synthesis. J Immunol 2002;169:3581-3588

26. Mühlbauer M, Fleck $M$, Schütz $C$, Weiss T, Froh $M$, Blank C, Schölmerich J, Hellerbrand C. PD-L1 is induced in hepatocytes by viral infection and by interferon-alpha and -gamma and mediates T cell apoptosis. J Hepatol 2006; 45:520-528

27. Yamazaki T, Akiba $H$, Iwai $H$, Matsuda $H$, Aoki $M$, Tanno Y, Shin T, Tsuchiya H, Pardoll DM, Okumura K, Azuma M, Yagita H. Expression of programmed death 1 ligands by murine T cells and APC. J Immunol 2002;169:5538-5545

28. Theise ND, Nimmakayalu M, Gardner R, Illei PB, Morgan G, Teperman L, Henegariu O, Krause DS. Liver from bone marrow in humans. Hepatology 2000;32:11-16

29. Kleeberger W, Rothämel T, Glöckner S, Flemming P, Lehmann U, Kreipe H. High frequency of epithelial chimerism in liver transplants demonstrated by microdissection and STR-analysis. Hepatology 2002;35:110-116

30. Wynn TA. Common and unique mechanisms regulate fibrosis in various fibroproliferative diseases. J Clin Invest 2007;117:524-529

31. Maier H, Isogawa M, Freeman GJ, Chisari FV. PD-1: PD-L1 interactions contribute to the functional suppression of virus-specific $\mathrm{CD} 8+\mathrm{T}$ lymphocytes in the liver. $\mathrm{J}$ Immunol 2007;178:2714-2720

32. Tsuda $M$, Matsumoto $K$, Inoue $H$, Matsumura $M$, Nakano T, Mori A, Azuma M, Nakanishi Y. Expression of B7-H1 and B7-DC on the airway epithelium is enhanced by double-stranded RNA. Biochem Biophys Res Commun 2005; 330:263-270 